\title{
Lack of role of endothelial nitric oxide synthase gene Glu298Asp polymorphism in rheumatoid arthritis among Asian Indians
}

\author{
Chingkheilemba $\mathrm{M}^{1}$, Uma Kumar ${ }^{2}$, Kunzang Chosdol $^{3}$, Nibhriti Das ${ }^{3}$ \\ ${ }^{I}$ Department of Biochemistry, Regional Institute of Medical Sciences, Manipur, India \\ ${ }^{2}$ Department of Medicine, All India Institute of Medical Sciences, New Delhi, India \\ ${ }^{3}$ Department of Biochemistry, All India Institute of Medical Sciences, New Delhi, India
}

\begin{abstract}
:
Aim: The aim of this study was to investigate the association of Glu298Asp polymorphism in the endothelial nitric oxide synthase (eNOS) gene with rheumatoid arthritis (RA) in Asian Indians.

Methods: We conducted a case control study in which 100 patients diagnosed with RA and 100 healthy controls were enrolled. DNA was extracted from peripheral blood and eNOS polymorphism was detected by PCR-RFLP. Plasma samples from the subjects were screened for nitric oxide (NO).

Results: There was a trend of increase of GG genotypic and G allelic frequencies of the eNOS gene Glu298Asp in patients when compared with controls. GT genotype emerged as major genotype in both controls and patients. Genotypes disobeyed Hardy-Weinberg equilibrium. Reduced NO levels was detected in patients as compared to controls. Patients with GG genotype and GT genotypes were found to have significantly low level of plasma NO as compared to controls with GG and GT genotypes.

Conclusions: eNOS gene Glu298Asp polymorphism is not associated with the susceptibility of rheumatoid arthritis in Asian Indians.
\end{abstract}

Key words: eNOS, Polymorphism, Rheumatoid arthritis

\section{Introduction}

Rheumatoid arthritis (RA) is one of the most common systemic inflammatory diseases. However, the exact mechanism of the disease is not clear [1]. It was suggested that nitric oxide (NO) plays an important role in the pathogenesis of rheumatoid arthritis. The level of NO is increased in rheumatoid arthritis patients [2], and a study suggested that $\mathrm{NO}$ can regulate the balance of Th1/Th2 in autoimmune diseases, and it was a key mediator of apoptosis within rheumatoid arthritis joints [3].

NO synthesis is tightly regulated by three forms of nitric oxide synthase (NOS) including neuronal synthases (nNOS or NOS1), inducible NOS (iNOS or NOS2), and endothelial NOS (eNOS or NOS3). Several functionally relevant polymorphisms in the iNOS and eNOS genes have been identified, which have been associated with many diseases, such as vascular disease, autoimmune disease, and infectious diseases [4].

The eNOS gene is located on chromosome 7q35-q36, and is a potential candidate gene in the regulation of the immune reaction as it can influence the production of $\mathrm{NO}$ and the risk of rheumatoid arthritis. One of the common polymorphisms in the eNOS gene is Glu298Asp polymorphism in exon 7 of the gene. Although many studies have shown the association between this polymorphism and some autoimmune diseases, the results are conflicting [5]. To date, no reports are available for the association of eNOS gene Glu298Asp polymorphism with rheumatoid arthritis in Asian Indian population. Hence, our main aim was to examine the possible association between the eNOS gene polymorphism and rheumatoid arthritis risk among Asian Indian population.

\section{Subjects}

\section{Materials and Methods}

One hundred rheumatoid arthritis patients were recruited from the Department of Rheumatology (Medicine) of the All India Institute of Medical Sciences (AIIMS), New Delhi. All the patients met the American College of Rheumatology 1987 revised criteria ${ }^{6}$, were 20 to 60 years old (mean age $(39.05 \pm 11.45)$ years). All the patients were on treatment for RA before recruitment. One hundred age- and ethnicity-matched normal volunteers comprising patient's relatives, students of AIIMS and voluntary blood donors of Blood Bank, AIIMS were studied as controls. All the controls were 20 to 60 years old (mean age (29.5 \pm 7.42$)$ years). Each participant donated peripheral blood for DNA analysis and plasma isolation. Plasma samples were stored at $-20{ }^{\circ} \mathrm{C}$ in aliquots until use. All study participants provided written informed consent and the study was approved by the local ethics committee. 


\section{DNA extraction}

Genomic DNA was isolated from peripheral blood leucocytes by the Miller extraction method [7].

\section{Analysis of the Glu 298 Asp polymorphism in exon 7 of the e NOS gene}

The genomic DNA was amplified by PCR using the following primers flanking the polymorphic region of eNOS gene: sense-5'TCC CTG AGG AGG GCA TGA GGC T-3' and anti-sense- 5' TGA CGG TCA CAC AGG TTC CT 3'. Samples were amplified for 30 cycles, consisting of denaturation at $95^{\circ} \mathrm{C}$ for 1 minute, annealing at $61{ }^{\circ} \mathrm{C}$ for 1 minute and extension at $72^{\circ} \mathrm{C}$ for 1 minute with a final extension of 10 minutes. Amplified products were run on a check gel with $1 \%$ agarose. The resulting 457-bp amplification product was digested with $8 \mathrm{U}$ of the Ban II restriction enzyme at $37^{\circ} \mathrm{C}$ for at least 20 hours. Ban II digested the amplified fragments into smaller fragments $(137$ and $320 \mathrm{bp}$ ). The restricted fragments were resolved on $2 \%$ agarose gels and visualized by ethidium bromide staining.

\section{Estimation of nitric oxide (NO)}

Plasma NO levels was evaluated using sodium nitrite $\left(\mathrm{NO}_{2}\right)$ as standard by acidic Griess reaction method [8].

\section{Statistical Methods}

Statistical analysis were performed according to SPSS(Statistical Package for Social Sciences) for windows(version 9.0.0, SPSS Inc., Chicago) and TFPGA (Tools for population genetic analysis) version 1.3 developed by Mark Miller from the department of biological science, North Arizona University. Frequency of genotypes (GG,GT, TT) and alleles (G,T) of Glu298Asp polymorphism in exon 7 of eNOS gene were assessed using Fisher's exact test and chi-square test wherever applicable. Mann Whitney test and Kruskal Wallis test were used wherever applicable. Unpaired and two tailed t tests were used to analyze laboratory data. $\mathrm{P}$ value $\leq 0.05$ was considered statistically significant.

\section{Results}

\section{Association of eNOS Glu298Asp Polymorphism and Rheumatoid arthritis}

On comparative evaluation of the frequency of Glu298Asp genotype and alleles between the patients and healthy subjects (Table 1), it was found that G allele and GG genotype are more prevalent in RA patients $(0.68 \& 41 \%)$ as compared to healthy subjects $(0.62$ and $27 \%)$. Odd's ratio (OR) of GG genotype was 1.88 (95\% CI=0.99-3.56, $\mathrm{p}=0.036)$ to develop Rheumatoid arthritis. The individuals carrying TT genotype, the OR to develop RA was insignificant as compared to $\mathrm{G}$ allele carriers $(\mathrm{GG}+\mathrm{GT})$. The plasma concentration of NO in a total of 100 patients and 100 healthy subjects was evaluated (Table 2). The results are expressed in micromolar $(\mu \mathrm{M})$. The plasma NO concentration was found to be extremely significant $(p<0.0001)$ in patients $(11.83 \pm$ 10.25) when compared to controls $(18.54 \pm 13.5)$.

\section{Relationship between eNOS Glu298Asp polymorphism and plasma NO in controls and patients}

Plasma levels of NO in individual genotypes in controls and patients are shown in Table 3. Patients with GG genotype and GT genotypes were found to have significantly low level of plasma NO as compared to controls with GG and GT genotypes $(\mathrm{p}=0.002, \mathrm{p}=0.001)$. Whereas there was no significant difference in plasma NO levels of controls and patients with TT genotype $(\mathrm{p}=0.18)$. There was no significant difference in plasma NO levels among patients with GG, GT and TT genotypes ( $p>0.05$ ). Likewise, there was no significant difference in plasma NO levels among controls with GG, GT and TT genotypes ( $p>0.05)$

\section{Discussion}

In this study, we investigated whether the eNOS gene Glu298Asp polymorphism is implicated in susceptibility to RA. We demonstrated here that there was a trend of increase of GG genotypic and G allelic frequencies of the eNOS gene Glu298Asp, respectively, in RA patients when compared with controls. Odd's ratio $(\mathrm{OR})$ of GG genotype was $1.88(95 \% \mathrm{CI}=0.99-3.56, \mathrm{p}=0.036)$ to develop Rheumatoid arthritis. This may suggest that majority of people are susceptible to RA. GT emerged as major genotype in both controls and patients suggesting that heterozygous are more protected against RA. However, in one study in our lab on the same polymorphism GG dominates over GT and TT genotypes [9]. Likewise in several other studies, GG dominates over GT and TT genotypes [10,11,12]. In our study, the distribution pattern did not obey Hardy Weinberg equilibrium. Therefore, not much importance can be ascribed to this finding. Moreover, previous findings referred to a Spanish cohort of RA patients did not support the implication of eNOS gene Glu298Asp polymorphism in susceptibility to RA [5]. Gonzalez et al revealed that inducible but not endothelial NOS polymorphism is associated with susceptibility to RA in Northwest Spain. There may be several reasons for the distribution pattern not obeying HW equilibrium. These include restriction in sample size, presence of natural 
selection, mutation, non-random mating and migration $[14,15]$. Therefore, one of the strategies should be to extend the study to a larger cohort.

We demonstrated that the plasma NO levels were significantly low in RA patients as compared to healthy controls. This may be due to higher oxidative stress associated with RA. ${ }^{16-20}$ Under the conditions of high levels of oxidants like oxygen free radicals, $\mathrm{NO}$ gets converted to injurious peroxynitrite radical $\left(\mathrm{ONOO}^{-}\right)$, which further may get isomerized to $\mathrm{NO}_{3}$ or get converted to nitrotyrosine $[21,22,23]$. The low level of $\mathrm{NO}$ in RA patients might explain for the relatively high prevalence of vascular pathology such as vasculitis among RA patients. This is because the production of NO by eNOS may offer a protective or anti-inflammatory function by preventing the adhesion and release of oxidants by activated neutrophils in the microvasculature [13]. Therapeutic modalities that restore deficiencies in NO or eNOS may be considered in the treatment of RA with vasculitis with caution.

Plasma NO levels were correlated with eNOS Glu298Asp polymorphism. We found that patients with GG genotype and GT genotypes were found to have significantly low level of plasma NO as compared to controls with GG and GT genotypes $(p=0.002, p=0.001)$. This finding is in consonance with another study from our lab [9] and previous other studies in relation to different diseases [3,24]. Whereas there was no significant difference in plasma NO levels of controls and patients with TT genotype ( $\mathrm{p}=0.18)$. At present, we are not able to provide an exact mechanism for this finding.

\section{Conclusions}

This study aimed at the elucidation of the relationship between eNOS gene Glu298Asp polymorphism and RA. The O.R. for GG genotype of the Glu298Asp polymorphism for RA was found to be 1.8 which suggested an association of this genotype with the risk of RA. However the distribution of the genotype did not obey Hardy-Wienberg equilibrium both in controls and patients and the normal distribution was found different than that reported earlier in another study from the same region. Therefore, further confirmation is needed in relation to the association of Glu298Asp polymorphism with RA. The plasma levels of NO were significantly lower in patients as compared to the controls suggesting a possible relationship between the lower levels of NO with the disease.

\section{Acknowledgement}

We thank all the volunteers who consented to participate in the study.

\section{Grant Support}

This study was supported by Indian Council of Medical Research, New Delhi, India.

\section{Conflict of interest}

The authors declare that they have no conflict of interest

\section{References}

[1] Suzuki A, Yamada R, Ohtake-Yamanaka M, Okazaki Y, Sawada T, Yamamoto K. Anti-citrullinated collagen type I antibody is a target of autoimmunity in rheumatoid arthritis. Biochem Biophys Res Commun. 2005 Jul 29;333(2):418-26.

[2] Yki-Jarvinen H, Bergholm R, Leirisalo-Repo M. Increased inflammatory activity parallels increased basal nitric oxide production and blunted response to nitric oxide in vivo in rheumatoid arthritis. Ann Rheum Dis 2003; 62: 630-634.

[3] Wang XL, Wang J. Endothelial nitric oxide synthase gene sequence variations and vascular disease. Mol Genet Metab 2000; 70 : 241-251.

[4] Burgner D, Xu W, Rockett K, Gravenor M, Charles IG, Hill AV, et al. Inducible nitric oxide synthase polymorphism and fatal cerebral malaria. Lancet.1998; 352: 1193-1194.

[5] Gonzalez-Gay MA, Llorca J, Sanchez E, Lopez-Nevot MA, Amoli MM, Garcia-Porrua C, et al. Inducible but not endothelial nitric oxide synthase polymorphism is associated with susceptibility to rheumatoid arthritis in northwest Spain. Rheumatology (Oxford) 2004; 43: 1182-1185.

[6] Arnett FC, Edworthy SM, Bloch DA, McShane DJ, Fries JF, Cooper NS, et al. The American Rheumatism Association 1987 revised criteria for the classification of rheumatoid arthritis. Arthritis Rheum 1988; 31:315-24.

[7] Miller SA, Dykes D, Polesky HF. A simple salting out procedure for extracting DNA from human nucleated cells. Nucleic acid Res 1988; 16: 1215.

[8] Ding A.H, Nathan C.F. and Stuehr D.J. Release of reactivenitrogen intermediates and reactive oxygen intermediates frommouse peritoneal macrophages. Journal of Immunology 1988, 141: 2407-2412

[9] Srivastava K, Narang R, Sreenivas V, Das S, Das N. Association of eNOS Glu298Asp gene polymorphism with essential hypertension in Asian Indians. Clin Chim Acta. 2008 Jan;387(1-2):80-3

[10] Eisei Noiri, Hiroaki Satoh, Jun-ichi Taguchi, Sergey V. Brodsky, Akihide Nakao, Yumiko Ogawa, Satomi Nishijima, Takehiko Yokomizo, Katsushi Tokunaga, Toshiro Fujita. Association of eNOS Glu298Asp Polymorphism With End-Stage Renal Disease. Hypertension. 2002;40:535-540.

[11] Mohsen Kerkeni, Faoouzi Addad, Maryline Chauffert, et al. Hyperhomocystenemia, endothelial nitric oxide synthase gene polymorphism and risk of coronary artery disease in Tunisia. Clinical chemistry 2006; 52: 53-58.

[12] Lale Afrasyap and Guler Ozturk. NO level and endothelial NO synthase gene polymorphism(Glu298Asp) in the patients with coronary artery disease from the Turkish Population. Acta Biochimica et Biophysica Sinica 2004; 36(10): 661-66. 
[13] Abramson SB, Amin AR, Clancy RM, AtturM. The role of nitric oxide in tissue destruction. Best Pract Res Clin Rheumatol 2001; $15: 831-845$

[14] Gillespie, J. H. Population Genetics: A Concise Guide, 2nd ed. Baltimore, MD: Johns Hopkins University Press, 2004

[15] Stearns, Stephen C., and Rolf F. Hoekstra. Evolution: An Introduction. New York: Oxford University Press, 2000

[16] De Leo ME, Tranghese A, Passantino M, Mordente A, Lizzio MM, Galeotti T, Zoli A Manganese superoxide dismutase, glutathione peroxidase, and total radical trapping antioxidant capacity in active rheumatoid arthritis. J Rheumatol. 2002 Oct;29(10):2245-6.

[17] Taysi S, Polat F, Gul M, Sari RA, Bakan E: Lipid peroxidation, some extracellular antioxidants, and antioxidant enzymes in serum of patients with rheumatoid arthritis. Rheumatol Int 2002, 21:200-204.

[18] Cimen MY, Cimen OB, Kacmaz M, Ozturk HS, Yorgancioglu R, Durak I: Oxidant/antioxidant status of the erythrocytes from patients with rheumatoid arthritis. Clin Rheumatol 2000, 19:275-277.

[19] Marklund SL, Bjelle A, Elmqvist LG: Superoxide dismutase isoenzymes of the synovial fluid in rheumatoid arthritis and in reactive arthritides. Ann Rheum Dis 1986, 45:847-851.

[20] Ozturk HS, Cimen MY, Cimen OB, Kacmaz M, Durak I: Oxidant/antioxidant status of plasma samples from patients with rheumatoid arthritis. Rheumatol Int 1999, 19:35-37

[21] Moncada S, Palmer RM, Higgs EA. Nitric oxide: physiology, pathophysiology, and pharmacology. Pharmacol Rev. 1991 Jun;43(2):109-42.

[22] Patel RP, Moellering D, Murphy-Ullrich J, Jo H, Beckman JS, Darley-Usmar VM. Cell signaling by reactive nitrogen and oxygen species in atherosclerosis. Free Radic Biol Med. 2000 Jun 15;28(12):1780-94.

[23] Szabo C. The Pathophysiological Role of Peroxynitrite in Shock, Inflammation, and Ischemia-Reperfusion Injury. Shock, 6 (1996), 79

[24] Cai H, Harrison DG Endothelial dysfunction in cardio vascular diseases. Circ Res (2000) 87:840-844

Table 1: Distribution of Glu298Asp Genotypes and Frequency of Alleles in Controls and Rheumatoid arthritis Patients

\begin{tabular}{|l|l|l|l|l|l|}
\hline & $\begin{array}{l}\text { Patients } \\
(\mathbf{N = 1 0 0})\end{array}$ & $\begin{array}{l}\text { Controls } \\
(\mathbf{N = 1 0 0 )}\end{array}$ & P value & O.R. & C.I. \\
\hline Genotypes & & & & & \\
\hline GG & 41 & 27 & 0.036 & 1.88 & $0.99-3.56$ \\
\hline GT & 54 & 30 & 0.02 & 0.5 & $0.27-0.94$ \\
\hline TT & 5 & 3 & 0.72 & 1.7 & $0.34-9.28$ \\
\hline GT+TT & 59 & 73 & & 0.53 & $0.28-1.01$ \\
\hline Alleles & & 0.62 & & & \\
\hline G & 0.68 & 0.38 & & & \\
\hline T & 0.32 & & & \\
\hline
\end{tabular}

Table 2: Plasma levels of NO in controls and RA patients

CONTROL PATIENTS

\begin{tabular}{|l|l|l|l|l|l|l|l|}
\hline Variable & Mean \pm SD & median & Range & Mean \pm SD & median & Range & P value \\
\hline NO & $18.54 \pm 13.5$ & 14.78 & $1.45-65.04$ & $11.83 \pm 10.25$ & 9.56 & $1.38-57.27$ & 0.001 \\
\hline
\end{tabular}

Table 3: Plasma NO level in relation to eNOS Glu298Asp polymorphism PATIENTS CONTROLS

\begin{tabular}{|l|l|l|l|l|l|l|}
\hline Genotype & Median & Mean \pm SD & Genotype & Median & Mean \pm SD & P value \\
\hline GG (41) & 9.76 & $11.95 \pm 10.3$ & GG (27) & 18.78 & $20.56 \pm 14.71$ & $\mathbf{0 . 0 0 2}$ \\
\hline GT (54) & 9.19 & $11.79 \pm 10.72$ & GT (70) & 13.38 & $17.97 \pm 13.35$ & $\mathbf{0 . 0 0 1}$ \\
\hline TT (5) & 9.92 & $11.2 \pm 4.12$ & TT (3) & 14.15 & $14.05 \pm 0.78$ \\
\hline
\end{tabular}

